\title{
Plasma and Particle Temperature Measurements in Thermal Spray: Approaches and Applications
}

\author{
Georg Mauer, Robert Vaßen, and Detlev Stöver
}

(Submitted September 16, 2010; in revised form November 3, 2010)

\begin{abstract}
Growing demands on the quality of thermally sprayed coatings require reliable methods to monitor and optimize the spraying processes. Thus, the importance of diagnostic methods is increasing. A critical requirement of diagnostic methods in thermal spray is the accurate measurement of temperatures. This refers to the hot working gases as well as to the in-flight temperature of the particles. This article gives a review of plasma and particle temperature measurements in thermal spray. The enthalpy probe, optical emission spectroscopy, and computer tomography are introduced for plasma measurements. To determine the in-flight particle temperatures mainly multicolor pyrometry is applied and is hence described in detail. The theoretical background, operation principles and setups are given for each technique. Special interest is attached to calibration methods, application limits, and sources of errors. Furthermore, examples of fields of application are given in the form of results of current research work.
\end{abstract}

Keywords Boltzmann plot, enthalpy probe, optical emission spectroscopy, particle temperature, plasma temperature, thermal spray, two-color pyrometry

\section{Introduction}

Thermally sprayed coatings are being used for more and more demanding applications. Thus, two main issues are becoming increasingly important: the development of new process parameters to realize specific coating properties and the monitoring of processing to ensure constant quality and reliability. Furthermore, in the case of new process developments, such as suspension-based thermal spraying, the characterization of working gases and inflight particles provides an understanding and supports optimization of these processes.

The functional chain within thermal spray processes starts with the setting and control of process input parameters such as gas flows, current, and powder feed rates, and it ends with quality-relevant coating properties such as the deposition rate, adhesion strength, or porosity. These variables are linked by the characteristics of the hot working gases as well as the particle in-flight state. Hence, it is desirable to have an interior view of the process by measuring such characteristics to control the process results. Even though not all mechanisms and effects are fully understood, deviations of these interior process variables may be detected so as to initiate the inspection of the

Georg Mauer, Robert Vaßen, and Detlev Stöver, Institut für Energie-und Klima forschung (IEK-1), Forschungszentrum Jülich GmbH, Jülich, Germany. Contact e-mail: g.mauer@fzjuelich.de.

equipment and corrective actions. This is of importance as thermal spray guns, in particular, are subjected to wear.

Several reviews (Ref 1-4) report on the rapid development of appropriate measurement techniques and sensor systems capable of working in the harsh environments of spray booths. A critical requirement is the accurate measurement of temperatures. This refers to the hot working gases as well as to the in-flight temperature of the particles. This article gives a review of plasma and particle temperature measurement techniques currently used for thermal spray processes. The enthalpy probe, optical emission spectroscopy, and computer tomography are introduced for plasma measurements. To determine the in-flight particle temperatures mainly multicolor pyrometry is applied und thus described here.

Such methods cannot be applied in a proper way without understanding their working principles. In particular, those techniques which are intended to be used in research and development rather than in industrial production require specific knowledge. Thus, in this article special interest is attached to calibration methods, operational limits, and sources of errors. Furthermore, examples of fields of application are given in the form of results of current research work.

\section{Plasma Temperature Measurement}

\subsection{Enthalpy Probe}

Enthalpy probes were developed in the 1960s and their applicability has been approved in many cases (Ref 5,6). Examples are the investigation of the impact of the ambient atmosphere on the characteristics of the plasma jet ( Ref 7), the understanding of nonequilibrium situations 


\begin{tabular}{|c|c|c|c|}
\hline \multicolumn{4}{|c|}{ Nomenclature } \\
\hline \multicolumn{2}{|r|}{ Latin alphabet } & $\begin{array}{l}N \\
p\end{array}$ & $\begin{array}{l}\text { population of species, - } \\
\text { pressure, } \mathrm{Pa}\end{array}$ \\
\hline$A_{j k}$ & $\begin{array}{l}\text { transition probability for the transition from } j \text { to } \\
k, \mathrm{~s}^{-1}\end{array}$ & $p_{g, 1}$ & $\begin{array}{l}\text { stagnation pressure measured at the probe exit, } \\
\mathrm{Pa}\end{array}$ \\
\hline$c$ & velocity of light, $\mathrm{m} \mathrm{s}^{-1}$ & $p_{g, \infty}$ & static ambient jet pressure, $\mathrm{Pa}$ \\
\hline$c_{p, \mathrm{w}}$ & cooling water specific heat, $\mathrm{J} \mathrm{kg}^{-1} \mathrm{~K}^{-1}$ & $r^{2}$ & coefficient of determination, - \\
\hline$d$ & diameter, $\mathrm{m}$ & $T$ & temperature, $\mathrm{K}$ \\
\hline E & $\begin{array}{l}\text { spectral thermal flux emitted by a surface } \\
\text { element } \mathrm{W} \mathrm{m}^{-3}\end{array}$ & $\begin{array}{l}\Delta T_{\mathrm{w}} \\
v_{\mathrm{g}, \infty}\end{array}$ & $\begin{array}{l}\text { rise in cooling water temperature, } \mathrm{K} \\
\text { free-stream plasma gas velocity, } \mathrm{m} \mathrm{s}^{-1}\end{array}$ \\
\hline$E_{i}$ & ionization energy of level $i, \mathrm{~J}$ & $V^{5, \infty}$ & volume, $\mathrm{m}^{3}$ \\
\hline$E_{j}$ & energy of level $j, \mathrm{~J}$ & $Z$ & partition function, - \\
\hline$g_{j}$ & statistical weight (degeneracy) of level $j$, - & & \\
\hline$h$ & Planck constant, J s & \multicolumn{2}{|r|}{ Greek alphabet } \\
\hline$h_{\mathrm{g}, 1}$ & $\begin{array}{l}\text { plasma gas enthalpy at the probe exit } \\
\text { thermocouple, } \mathrm{J} \mathrm{kg}^{-1}\end{array}$ & & emissivity, - \\
\hline$h_{\mathrm{g}, \infty}$ & plasma gas enthalpy at the probe entrance, $\mathrm{J} \mathrm{kg}^{-1}$ & $\lambda$ & wavelength, $\mathrm{m}$ \\
\hline$i^{b / 2}$ & ionization level, - & $\lambda_{j k}$ & wavelength of the emission due to the transition \\
\hline$I_{\Delta \lambda}$ & emissivity within filter band width $\Delta \lambda, \mathrm{W} \mathrm{m}^{-2}$ & & from $j$ to $k, \mathrm{~m}$ \\
\hline$I_{j k}$ & absolute intensity of a spectral line due to the & $\Delta \lambda$ & filter band width, $\mathrm{m}$ \\
\hline & transition from $j$ to $k, \mathrm{~W} \mathrm{~m} \mathrm{~m}^{-2}$ & $\rho_{\mathrm{g}, \infty}$ & free-stream plasma gas mixture mass density, \\
\hline$j$ & excited state, - & & $\mathrm{kg} \mathrm{m}^{-3}$ \\
\hline$k$ & lower energy state, - & \multicolumn{2}{|r|}{ Abbreviations } \\
\hline $\begin{array}{l}k_{B} \\
K_{1}\end{array}$ & $\begin{array}{l}\text { Boltzmann constant, } \mathrm{J} \mathrm{K}^{-1} \\
\text { first radiation constant, } \mathrm{W} \mathrm{m}{ }^{2}\end{array}$ & $\mathrm{CCD}$ & charge-coupled device \\
\hline$K_{2}$ & second radiation constant, $\mathrm{m} \mathrm{K}$ & $\mathrm{CT}$ & computer tomography \\
\hline$L$ & emission source depth, m & $\mathrm{EtOH}$ & ethanol \\
\hline$m$ & energy level, - & LPPS & low pressure plasma spraying \\
\hline$m$ & slope of Boltzmann plot, $\mathrm{J}^{-1}$ & LTE & local thermal equilibrium \\
\hline$m_{\mathrm{e}}$ & electron mass, $\mathrm{kg}$ & NIST & National Institute of Standards and Technology \\
\hline$\dot{m}_{\mathrm{g}}$ & gas sample mass flow rate, $\mathrm{kg} \mathrm{s}^{-1}$ & slpm & standard liters per minute \\
\hline$\dot{m}_{\mathrm{w}}$ & cooling water mass flow rate, $\mathrm{kg} \mathrm{s}^{-1}$ & SPS & suspension plasma spraying \\
\hline$n$ & density of atoms/ions, $\mathrm{m}^{-3}$ & SSMI & spray stream melting index \\
\hline$n_{\mathrm{e}}$ & electron density, $\mathrm{m}^{-3}$ & YSZ & yttria stabilized zirconia \\
\hline
\end{tabular}

in plasma jets (Ref 8 ), demixing effects and entrainment of surrounding cold gas with effects on plasma-particle interaction (Ref 9), nozzle design and optimization (Ref $10,11)$, oxidation control in different plasma gas compositions (Ref 12), and the characterization of new plasma torch concepts (Ref 13).

2.1.1 Theoretical Approach and Operation Principle. The enthalpy probe is a water-jacketed gas sampling and stagnation probe for studying the enthalpy, temperature, and velocity of hot and plasma gas flow fields. The probe itself consists of double-walled tubing usually made of stainless steel, which is cooled by a highpressure water circuit. Furthermore, the measured gas can be sampled to analyze its composition by integrating a mass spectrometer.

Figure 1 shows the operation principle (Ref 14, 15). At first a "tare" measurement is performed. Observations of the coolant temperature rise and flow rate are made while no plasma gas is flowing through the probe. Subsequently, the coolant measurements are repeated while the plasma gas sampling valve is opened ("sample" measurement) and the gas flow rate and the gas temperature at the probe exit are determined. The rate of heat removal from the gas sample can be calculated from the temperature differences of the cooling water between supply and return of the probe:

$\dot{m}_{\mathrm{g}}\left(h_{\mathrm{g}, \infty}-h_{\mathrm{g}, 1}\right)=\left(\dot{m}_{\mathrm{w}} c_{p, \mathrm{w}} \Delta T_{\mathrm{w}}\right)_{\text {sample }}-\left(\dot{m}_{\mathrm{w}} c_{p, \mathrm{w}} \Delta T_{\mathrm{w}}\right)_{\text {tare }}$

where $\dot{m}_{\mathrm{g}}$ is the gas sample mass flow rate, $\dot{m}_{\mathrm{w}}$ is the cooling water mass flow rate, $h_{\mathrm{g}, \infty}$ is the unknown gas enthalpy at the probe entrance, $h_{\mathrm{g}, l}$ is the gas enthalpy at the probe exit thermocouple, $c_{p, \mathrm{w}}$ is the cooling water specific heat, and $\Delta T_{\mathrm{w}}$ is the rise in cooling water temperature. The unknown gas enthalpy $h_{\mathrm{g}, \infty}$ can now be uniquely determined, provided that the gas sample flow rate $\dot{m}_{\mathrm{g}}$ and the gas enthalpy $h_{\mathrm{g}, l}$ at the probe exit are known. The latter is derived from the measured gas temperature at atmospheric pressure and the gas sample flow rate is determined via a sonic orifice or a mass flow meter. For both calculations the plasma gas composition is nee- 

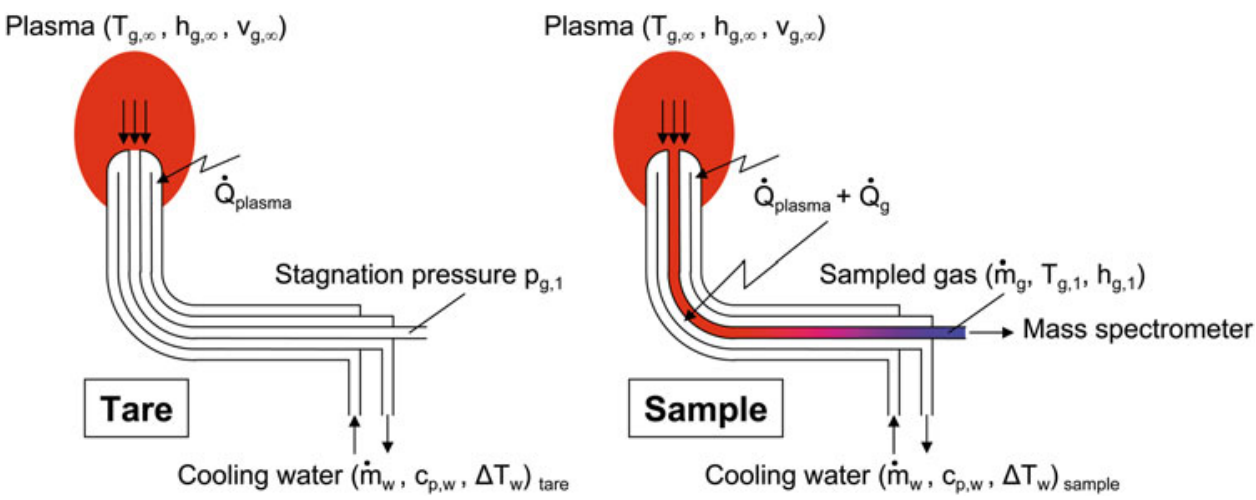

Fig. 1 Operation principle of the enthalpy probe (refer to the text for a description of the symbols)

ded, which is provided by the mass spectrometric analysis of the sampled gas. This is used to calculate the mass density as well as the specific enthalpy temperature relation of the plasma gas mixture based on tabulated values of its constituents. Finally, the plasma gas temperature is obtained from the plasma gas enthalpy $h_{\mathrm{g}, \infty}$, which is determined as described above and from the above-mentioned enthalpy temperature relation.

Moreover, the local plasma velocity at the sampling point is determined in the "tare" mode from the measured stagnation pressure in the dead-ended probe by Bernoulli's equation, which is valid for low subsonic gas flows:

$v_{\mathrm{g}, \infty}=\sqrt{\frac{2}{\rho_{\mathrm{g}, \infty}}\left(p_{g, 1}-p_{g, \infty}\right)}$

where $v_{\mathrm{g}, \infty}$ is the unknown free-stream plasma gas velocity, $\rho_{\mathrm{g}, \infty}$ is the free-stream plasma gas mixture mass density, $p_{g, 1}$ is the stagnation pressure measured at the probe exit, and $p_{g, \infty}$ is the static ambient jet pressure.

2.1.2 Realization and Limitations. The effectiveness of the enthalpy probe technique is dependent on the reproducibility of the flow conditions in the "tare" and the "sample" mode. This is achieved by making measurements under isokinetic conditions meaning that the gas velocity at the probe entrance is equal to the free gas stream velocity $v_{\mathrm{g}, \infty}$. Such conditions can be provided by adjusting the sample gas flow through the probe. Since the free gas stream velocity $v_{\mathrm{g}, \infty}$ is not known in advance the optimum sample gas flow has to be approached by an iterative procedure involving repeated measurements.

The coolant flow should be high enough so that, on the one hand, a proper thermal protection of the probe is ensured. On the other hand, too large a flow will result in only a small temperature rise thus affecting the measurement accuracy. According to experience, it is recommended to adjust the flow so that the temperature rise $\Delta T_{\mathrm{w}}$ is between 10 and $50 \mathrm{~K}$. For common systems, this refers to a heat flux of 1.0 to $1.5 \mathrm{~kW}$. As the maximum flow rate is limited by the probe dimension, this always implies restrictions for the application of enthalpy probes. Furthermore, a certain local heat flux due to the sampled hot plasma gas $h_{\mathrm{g}, \infty} \rho_{\mathrm{g}, \infty} v_{\mathrm{g}, \infty}$ must not be exceeded to avoid thermal damage to the probe. Maximum allowable values are typically between 100 and $150 \mathrm{MW} \mathrm{m}^{-2}$.

When measuring plasmas containing hydrogen downstream where the quantity of entrained air is considerable, $\mathrm{OH}$ radicals may be formed and trapped with $\mathrm{H}$ atoms at the relatively cold probe surface. Thus, the oxygen and hydrogen measurement could be biased.

2.1.3 Calibration. As the calculation of the plasma temperature relies on an energy balance which is performed on the cooling water into the probe and the measurement of the gas flow rate, the accuracy of the measurement of the water temperature and the flow rate is a key element for precise measurement. Thus, a special electrical heating element mounted on the probe is used to calibrate or simply to verify the calibration. A controller allows the adjustment and the measurement of the power dissipated in the heating element. At different flow rates, the error due to the water flow meter and the resistance temperature devices is determined under steady state conditions. Based on this, calibration factors are computed and saved. Once such a full calibration of the system has been completed, a new calibration run should be performed applying the calibration factors obtained previously to confirm and fine tune the accuracy. Normally, an accuracy of within $1 \%$ can be obtained in 2 to 3 calibrations.

2.1.4 Examples of Results. The enthalpy probe technique was applied to the suspension plasma spray process to improve the understanding of the effects taking place in the plasma plume due to the injection of suspension fluids. Thus, the effects of carrier gas flow, injection of ethanol and water on the characteristics of the plasma jet were investigated using an $\mathrm{F} 4$ torch and $\mathrm{Ar} / \mathrm{H}_{2}$ plasma (Ref 16). For the measurements, only the carrier liquid without particles was injected instead of the suspension.

This study was with a Triplex I plasma torch (Ref 17, 18). Examples of the results of current research work are given in the following. The plasma gas composition was $40 \mathrm{slpm} \mathrm{Ar}$ and $10 \mathrm{slpm} \mathrm{He}$, the current was $250 \mathrm{~A}$ corresponding to an input power of $17.3 \mathrm{~kW}$. The air injection flow was $4 \mathrm{~L} / \mathrm{min}$ and the EtOH flow was $0.05 \mathrm{~L} / \mathrm{min}$. The enthalpy probe system (ENP-04-CS, Tekna Plasma Systems Inc., Sherbrooke, QC, Canada) was used to determine the local enthalpy, temperature, and velocity of the 

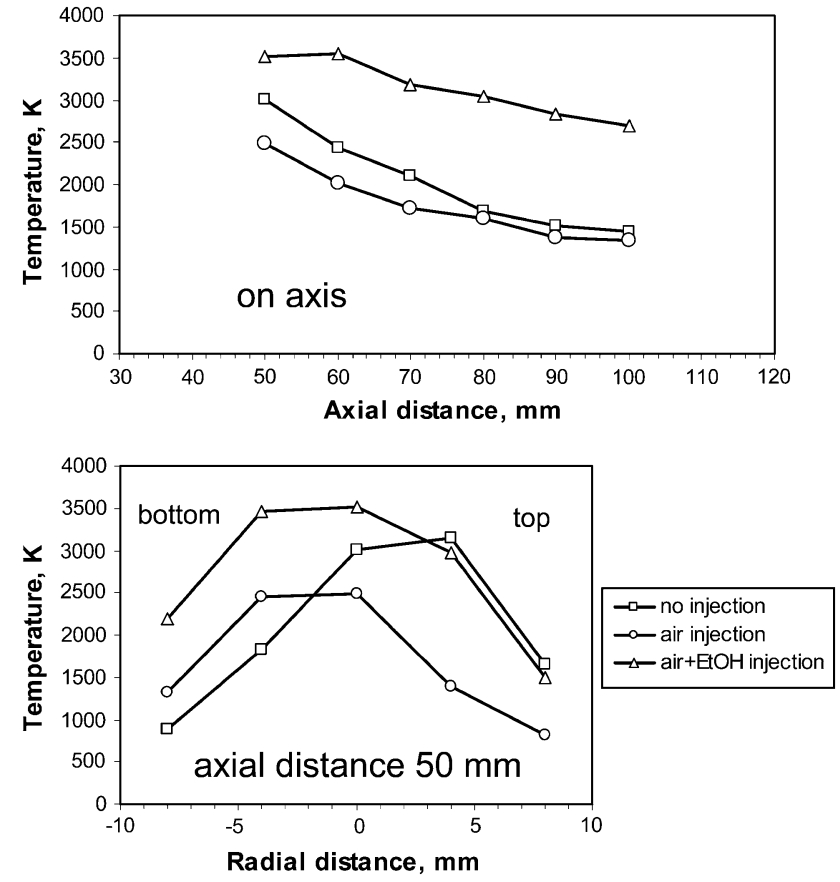

Fig. 2 Axial and radial distribution of the measured plasma gas temperatures for three cases, (a) without any injection (no injection), (b) injection of air without ethanol (air injection), and (c) two-phase injection of ethanol and air (air $+\mathrm{EtOH}$ injection) (Ref 17)

plasma. The outer diameter of the appropriate probe tube was $4.76 \mathrm{~mm}$ and the inner diameter $1.27 \mathrm{~mm}$. All measurements were performed under close to isokinetic conditions as explained above. The shortest measurement distance to the nozzle was $50 \mathrm{~mm}$ to avoid thermal overload of the probe tip by excessive local heat flux. The plasma gas composition was analyzed by means of a quadrupole mass spectrometer (Prisma QMS 200, Balzers AG, Balzers, Liechtenstein), which was calibrated by several known gas mixtures.

Figure 2 shows the measured plasma gas temperatures for three cases, (a) without any feedstock injection (no injection), (b) injection of air without ethanol (air injection), and (c) two-phase injection of ethanol and air (air $+\mathrm{EtOH}$ injection). The injection of air cools down the plasma plume. Furthermore, the radial temperature distribution is shifted downwards. At an axial distance of $50 \mathrm{~mm}$, the maximum is moved down in a radial direction by approximately $5 \mathrm{~mm}$. Apparently, the plasma gas flow is slightly deflected by the radial air injection. However, the cooling effect appears quite moderate. If ethanol is added the temperatures are enhanced considerably. The maximum temperature at a nozzle distance of $50 \mathrm{~mm}$ rises from $2458 \mathrm{~K}$ (air injection) to $3487 \mathrm{~K}$ (air + EtOH injection).

The measured velocity distributions in the plasma gas for the same three cases mentioned above (not described in detail in this article) show identical evolutions to the temperatures. Due to air injection, the velocities measured at a nozzle distance of $50 \mathrm{~mm}$ are lowered from $379 \mathrm{~m} \mathrm{~s}^{-1}$
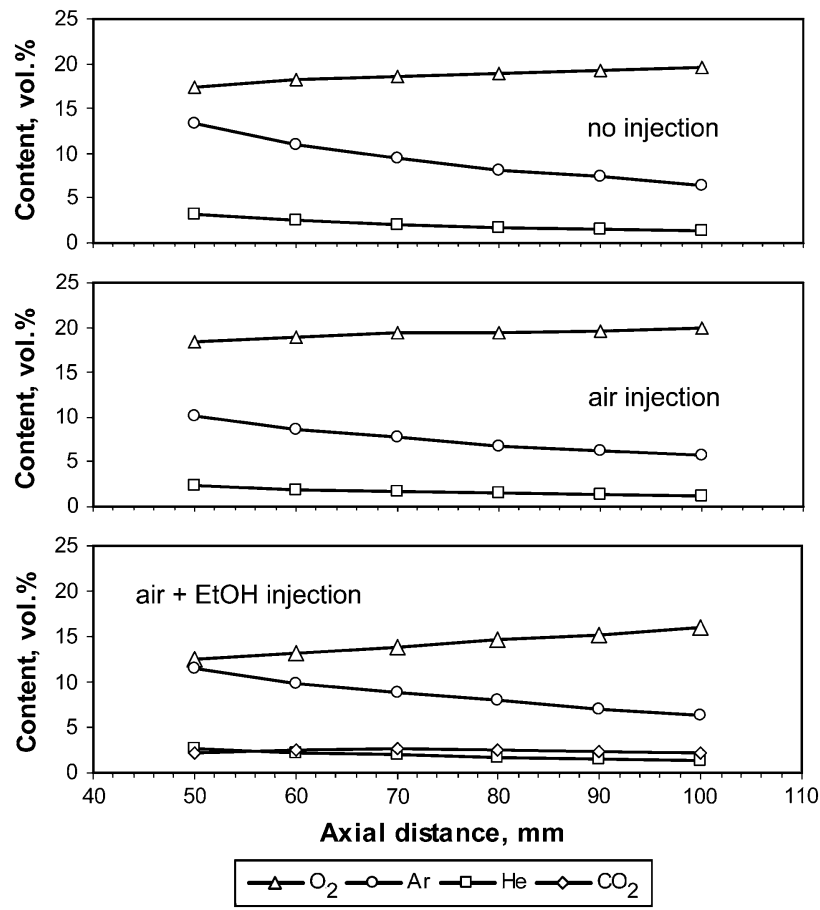

Fig. 3 Development on axis of the gas composition in the jet for operation (a) without any injection (no injection), (b) with injection of air only (air injection), and (c) for two-phase injection of ethanol and air (air + EtOH injection) (Ref 18)

(no injection) to $336 \mathrm{~m} \mathrm{~s}^{-1}$ (air injection). With ethanol, the combustion leads again to an increase in average flow velocity to $402 \mathrm{~m} \mathrm{~s}^{-1}$ (air + EtOH injection).

Figure 3 shows that in the case of ethanol injection the plasma gas displays a distinct $\mathrm{CO}_{2}$ content while the oxygen fraction is reduced by the combustion. In the axial direction, the maximum $\mathrm{CO}_{2}$ content of $2.65 \mathrm{vol} . \%$ is reached at a distance of $70 \mathrm{~mm}$ indicating that the combustion is completed here. At the same point, the oxygen content is lowered by combustion from 19.5 vol.\% (air injection only) to 13.8 vol.\% with ethanol. For the most part, the oxygen comes from the surrounding atmosphere. Without any injection, the oxygen measured on the axis at a distance of $50 \mathrm{~mm}$ is already 17.4 vol.\%, see Fig. 3. This shows that the entrainment of air into the plume takes place quite close to the nozzle. Such phenomena were already investigated by Pfender et al. (Ref 19). Thus, the combustion of species resulting from ethanol decomposition can take place at an early stage. The enthalpy probe measurements show that this combustion results in a gain of plasma enthalpy and consequently in higher plasma temperatures and velocities. This is due to the combustion enthalpies of the decomposition products, which are large, compared to the evaporation heat of ethanol.

\subsection{Optical Emission Spectroscopy}

The optical emission spectrum of plasma is a valuable characteristic for determining the plasma temperature. 
However, above all, optical emission spectroscopy allows the qualitative analysis of the emitting gas species including vaporized particle material and gaseous decomposed constituents of powderous and liquid feedstock.

2.2.1 Realization and Requirements. Suitable spectrometers must cover the visible and near-IR wavelength range of the selected spectral lines with reasonable accuracy and resolution. Modern spectroscopes generally use a dispersive element (e.g., a diffraction grid) and some kind of photodetector such as a diode array. The spectral resolution depends on the width of the entrance slit, the resolution of the detector itself as well as on the accuracy of the diffraction, which in the case of a grid is determined by the density of grooves in it. Spectral resolutions better than $0.5 \mathrm{~nm}$ can be obtained. If transient plasma conditions are to be investigated, also the velocity of the detectors and controllers must be considered. In particular, plasma spray jets generated by one-cathode torches may exhibit strong axial and longitudinal fluctuations so that only time-averaged measurements are obtainable. To provide a specific spatial measurement resolution, the plasma radiation is collected through a focusing lens from a small measurement volume. Optical fibers can be applied to transfer the light to the spectrometer entrance.

As the plasma jets are optically thin the measurement is spatially integrated along the line of sight of the optical sampling setup (Ref 20). To obtain the central characteristics of the plasma jet, generally a deconvolution of the measured two-dimensional projections of the integrated intensities must be performed to reconstruct the spatial plasma temperature field. This is commonly done by Abel inversion based on the assumption of axial symmetry. This way, the maximum values of radial profiles can be properly determined. In contrast, the integrated values are lower. Alternative methods have also been developed to circumvent Abel inversion (Ref 21, 22).
2.2.2 Examples of Results. The following spectroscopic measurements were performed by suspension plasma spraying applying a Triplex II gun (Ref 18). The plasma current was $500 \mathrm{~A}$ and the plasma gas flow $50 \mathrm{slpm}$ Ar with 4 slpm He yielding an input power of $56.2 \mathrm{~kW}$. The spray distance was $65 \mathrm{~mm}$. The powder used for the suspension was partially yttria-stabilized zirconia (5YSZ) from Tosoh Corporation (Tokyo, Japan). It was ball milled by a grinding stock of zirconia balls to obtain particle sizes in the suspension below $1 \mu \mathrm{m}$. The $20 \mathrm{wt} \%$ YSZ suspension was prepared by dispersing the powder in ethanol (EtOH).

The radiation of the jet was analyzed by optical emission spectrometry (MCS UV-NIR spectrometer, Carl Zeiss MicroImaging, Göttingen, Germany) in the 190 to $1020 \mathrm{~nm}$ wavelength range with a spectral pixel dispersion of approximately $0.8 \mathrm{~nm}$ per diode. Between 220 and $1000 \mathrm{~nm}$, the absolute accuracy was $<0.3 \mathrm{~nm}$, the relative accuracy was $<0.1 \mathrm{~nm}$, and the spectral resolution was $3 \mathrm{~nm}$. This is sufficient to identify qualitatively the emitting gas species. Plasma radiation was collected through a $2 \mathrm{~mm}$ vertical slit mask located $125 \mathrm{~mm}$ from the horizontal gun axis. Due to the optical-fiber-based setup, it was not possible to resolve the vertical profile of the plasma emission and thus to obtain the radial distribution using Abel inversion. Therefore, the collected intensities result from the integration of the spectral intensity. Thus, slight changes of the plasma symmetry due to the injection of the atomized liquid did not affect the measurement results.

Figure 4 shows the optical emission spectra at $20 \mathrm{~mm}$ axial distance from the nozzle for the three cases (a) without any injection (no injection), (b) two-phase injection of ethanol and air (air + EtOH injection), and (c) twophase injection of air and YSZ ethanol suspension (injection of air + YSZ EtOH suspension). Both the latter cases differ from the first case by some $\mathrm{C}$ and $\mathrm{H}$ peaks

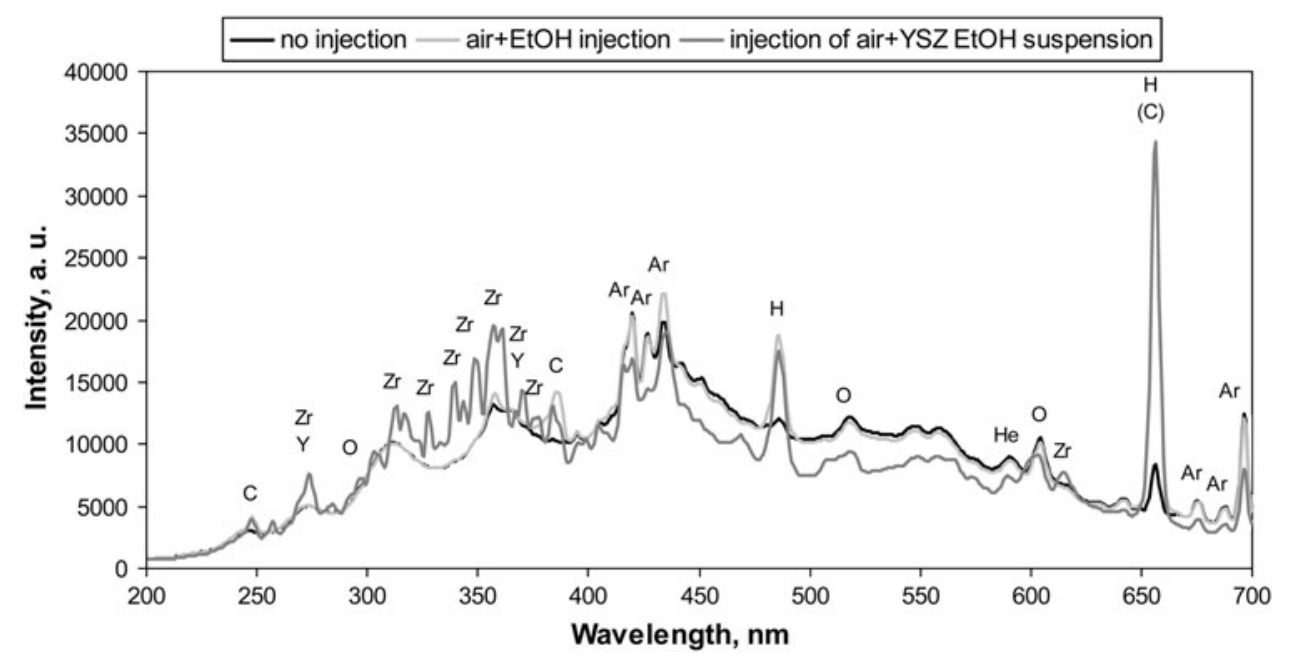

Fig. 4 Optical emission spectra at $20 \mathrm{~mm}$ axial distance for the three cases, (a) without any injection (no injection), (b) two-phase injection of ethanol and air (air + EtOH injection), and (c) two-phase injection of air and YSZ ethanol suspension (injection of air + YSZ EtOH suspension) (Ref 18) 
resulting from decomposed ethanol. The injection of YSZ EtOH suspension leads to several $\mathrm{Zr}$ and $\mathrm{Y}$ peaks, in particular between 270 and $380 \mathrm{~nm}$. The plasma gas Ar shows distinct peaks between 400 and $450 \mathrm{~nm}$ as well as above $700 \mathrm{~nm}$. Only one He peak is detected at $587.6 \mathrm{~nm}$, and other He peaks are apparently covered.

Obviously, the peaks corresponding to plasma gas species $\mathrm{Ar}$ and $\mathrm{He}$ show smaller intensities if the YSZ suspension is injected compared to the cases without injection and with injection of air and ethanol only. Since the plasma gas flow rates and thus the concentrations were the same, it is assumed that the gas temperature is lowered by the particle injection.

The spectral analysis proves the existence of evaporated YSZ material. Furthermore, there is a particle loading effect as reported in Ref 23. The particles consume part of the plasma energy for heating and also for evaporation as confirmed by the spectral $\mathrm{Zr}$ and $\mathrm{Y}$ peaks. The existence of evaporated particle material close to the nozzle is consistent with the fact that even if the material is not yet molten considerable vapor pressures are to be expected. The vapor pressure of zirconia reaches nearly $100 \mathrm{~Pa}$ (Ref 24) before reaching the melting point at 2983 K (Ref 25).

\subsection{Boltzmann Plot}

Based on spectroscopically measured emissions, plasma temperatures can be determined by the atomic Boltzmann plot method (Ref 26, 27).

2.3.1 Theoretical Approach. Applying the Boltzmann distribution, which is valid for local thermal equilibrium (LTE), the absolute intensity $I_{j k}$ of a spectral line emitted by the plasma due to the transition from an excited state $j$ to a lower energy state $k$ is

$I_{j k}=\frac{L h c}{4 \pi \lambda_{j k}} A_{j k} n \frac{g_{j}}{Z} e^{\left(-E_{j} / k_{B} T\right)}$

where $L$ is the emission source depth, $h$ is the Planck constant, $c$ is the velocity of light, $A_{j k}$ is the transition probability, $n$ is the density of emitting atoms/ions, $g_{j}$ is the statistical weight (degeneracy) of the excited level $j, \lambda_{j k}$ the wavelength of the emission, $Z$ is the partition function, $E_{j}$ the energy of the excited level, $k_{B}$ the Boltzmann constant, and $T$ the excitation temperature. If the intensities of a set of emission lines of the same final state are measured a linear plot

$\ln \left(\frac{I_{j k} \lambda_{j k}}{g_{j} A_{j k}}\right)=\frac{-E_{j}}{k_{B} T}+C, \quad C=\ln \left(\frac{L h c n}{4 \pi Z}\right)$

will yield a slope that is inversely proportional to the desired excitation temperature $T$. As a possible calibration factor between absolute and measured intensities $I_{j k}$ also vanishes in the constant $C$, the measurement of relative intensities is sufficient.

To establish a Boltzmann plot, a set of well-defined, isolated, and non-absorbing spectral lines have to be selected for one species of the plasma gas constituents and for the same ionization state. In many cases, this is neutral argon (Ar I). The lines must be selected carefully as a good emitter is at the same time a good absorber according to Kirchhoff's law of thermal radiation. Compared to low pressures, such absorbing effects increase at atmospheric conditions since the plasma becomes less optically thin. Generally, peaks measured at atmospheric pressure are wider when compared to those measured under vacuum conditions due to broadening effects that also explain the continuum background radiation (Ref 28). Such continuum radiation must be taken into account if the spectral resolution of the spectrometer is poor so that its intensity is considerable when compared to the discrete line intensity. The energies $E_{j}$ of the upper states should spread over a wide range for the selected lines to provide a good sensitivity and the least uncertainty of the Boltzmann plot method.

For each spectral line at wavelength $\lambda_{j k}$ the term on the left side of Eq 4 is calculated using the measured line intensity $I_{j k}$ and then plotted against the corresponding energy of the excited level $E_{j}$, which can be looked up in appropriate databases or reference books, as can the values of the transition probability $A_{j k}$ and the statistical weight $g_{j}$. Then a linear regression line is fitted to the data points. Finally, the desired excitation temperature may be derived directly from its slope $m$ by

$T=\frac{1}{m k_{B}}$

2.3.2 Realization and Limitations. As mentioned above, one basic assumption for applying the Boltzmann distribution is LTE. Chen et al. (Ref 29) compared temperatures derived from spectroscopically measured absolute emission coefficients and those achieved by an enthalpy probe. They used an SG-100 torch (Praxair, Inc., Danbury, CT, USA, formerly Miller Thermal, Inc.) operated at 800 A current with 47 slpm Ar and 22 slpm $\mathrm{He}$ as primary and secondary plasma gas, respectively. Substantial discrepancies were found exceeding by far the error limits inherent for both methods. The higher temperature values obtained from spectroscopy were interpreted to be due to strong nonequilibrium effects, in particular under turbulent conditions beginning at short distances downstream from the nozzle exit. Rajabian et al. (Ref 30) also compared these measurement methods and pointed out that in temperature regions below $4000 \mathrm{~K}$ the enthalpy probe method has to be used since the emission of the plasma is no longer adequate for emission spectroscopy. For Ar I lines, Joshi et al. (Ref 31) report a lower temperature limit of $5000 \mathrm{~K}$ for the application of emission spectroscopy.

2.3.3 Examples of Results. Optical emission spectra were collected for two low pressure plasma spray (LPPS) conditions at $150 \mathrm{~Pa}$ Ar pressure through the window of the process chamber. The plasma source was an $\mathrm{O} 3 \mathrm{CP}$ torch (Sulzer Metco AG, Wohlen, Switzerland) operated without powder injection. The plasma parameters were $35 \mathrm{slpm} \mathrm{Ar}$ and $60 \mathrm{slpm} \mathrm{He}$, in the one case the current was $2600 \mathrm{~A}$, in the other case the current was $2200 \mathrm{~A}$ with additionally 10 slpm $\mathrm{H}_{2}$ gas flow. In both the conditions, 
the input power was $112 \mathrm{~kW}$. As the spectra have to be evaluated quantitatively for this application the spectrometer (Ocean Optics, Dunedin, FL, USA) had an enhanced resolution when compared to the system described above. It is equipped with a 2048 element CCD array and covers the wavelength range from 360 to $800 \mathrm{~nm}$.

32 readily identifiable Ar I atomic spectral lines were selected between 516.2285 and $763.5106 \mathrm{~nm}$ to draw the Boltzmann plots. Figure 5 shows one example. The atomic spectra data were taken from NIST (Ref 32). It can be assumed that the plasma conditions are close to local thermal equilibrium as the plots show linear developments. The coefficients of determination for the regression lines are always $r^{2}>0.88$.

Figure 6 shows axial developments of plasma excitation temperatures determined by Boltzmann plots for the two mentioned conditions. Using the first case only $\mathrm{Ar}$ and $\mathrm{He}$ as plasma gases, the temperature decreases continuously in the downstream direction dropping below $10,000 \mathrm{~K}$ at $435 \mathrm{~mm}$ axial distance. The second case using additionally 10 slpm $\mathrm{H}_{2}$ exhibits lower temperatures as the dissociation of hydrogen molecules $\mathrm{H}_{2} \rightarrow 2 \mathrm{H}$ consumes energy.

\subsection{Computer Tomography}

Using computer tomography (CT) it is possible to spectroscopically measure plasma temperatures of even nonrotationally symmetric jets as no Abel inversion is required (Ref 33, 34).

2.4.1 Theoretical Approach and Realization. A number of individual measurements are each made at different angles around a half-circle of the jet. An analysis of the results, however, has to rely on temporal stability of the object examined as the images are subsequently taken during a time span of a few seconds. Hence, its primary application is for the more stable multi-electrode plasma torches.

To determine the temperature distribution, the CT system uses three individual cameras on a single turning unit. Each of these cameras moving in steps around the plasma jet is equipped with a different narrow-band

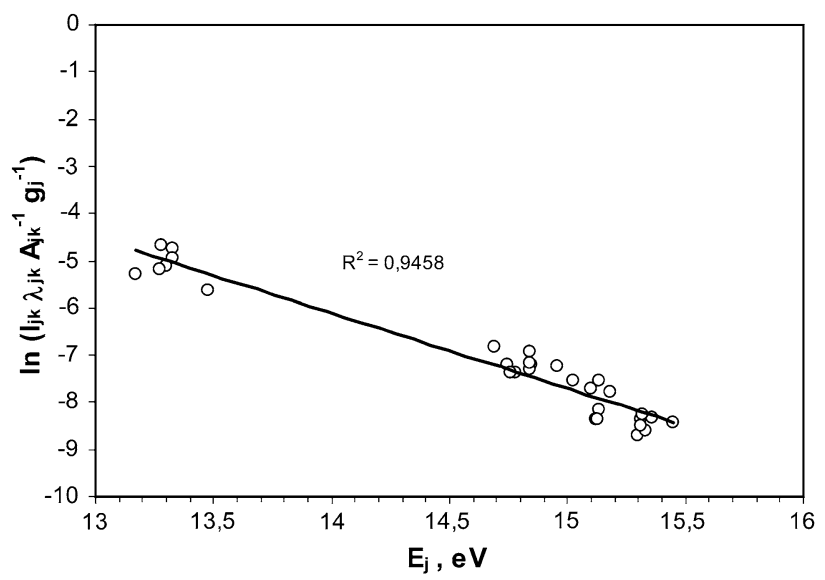

Fig. 5 Example of a Boltzmann plot for low pressure plasma spraying conditions plasma gas flow 35 slpm Ar, 60 slpm He and 10 slpm $\mathrm{H}_{2}$, current $2200 \mathrm{~A}$, and $1200 \mathrm{~mm}$ axial distance

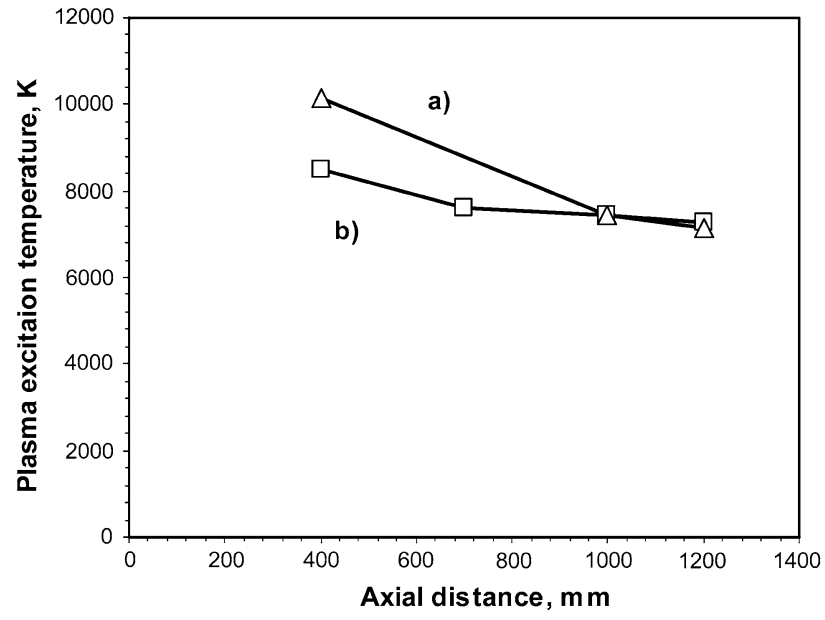

Fig. 6 Axial developments of plasma excitation temperatures for two low pressure plasma spraying conditions for (a) plasma gas flow 35 slpm Ar and 60 slpm He, current $2600 \mathrm{~A}$ and (b) plasma gas flow $35 \mathrm{slpm} \mathrm{Ar}, 60 \mathrm{slpm} \mathrm{He}$ and 10 slpm $\mathrm{H}_{2}$, current 2200 A

interference filters associated with one main line of a plasma gas constituent. For every cross section, an intensity distribution in the defined wavelength interval is tomographically reconstructed.

The temperature at this point can be determined using the measured ratios of intensity for each position and two wavelengths at a time, and comparing these ratios with theoretically calculated values for radiation emitted at LTE conditions. The calculation procedure starts with Eq 3 in combination with the partition function

$Z_{i}=\sum_{m} g_{m} e^{-E_{m} / k_{B} T}$

which has to be calculated for the neutral state $i=0$ and for the ionization levels $i=1,2 \ldots$ each by summation over all corresponding energy levels $m$.

Furthermore, the density $n$ of plasma gas species can be determined based on the following set of four equations

$$
\begin{aligned}
\frac{n_{\mathrm{e}} n_{i+1}}{n_{i}} & =\frac{2 Z_{i+1}}{Z_{i}}\left(\frac{2 \pi m_{\mathrm{e}} k_{B} T}{h^{2}}\right)^{3 / 2} e^{-\frac{E_{i+1}-E_{i}}{k_{B} T}} \\
& =K_{i} \quad \text { (Saha's equation assuming LTE) }
\end{aligned}
$$

where $n_{\mathrm{e}}$ is the electron density, $n_{0}$ and $n_{i}$ are the densities of the neutral and ionized species, respectively, $m_{\mathrm{e}}$ is the electron mass, and $E_{i}$ the ionization energy of level $i$.

For a given external pressure $p$ is the total density $n$ of species

$n=\frac{N}{V}=\frac{p}{k_{B} T} \quad$ (ideal gas law $)$

where $N$ is the population of species and $V$ is the gas volume. Considering the neutral state $(i=0)$ and the first $(i=1)$ and second $(i=2)$ ionization level, which are relevant for plasma spray conditions, the total density $n$ of species is 
$n=n_{\mathrm{e}}+n_{0}+n_{1}+n_{2} \quad$ (derived from Dalton's law)

and the electron density $n_{\mathrm{e}}$ is

$n_{\mathrm{e}}=n_{1}+2 n_{2} \quad$ (electroneutrality condition)

Taking Eq 7-10 together, the electron density $n_{\mathrm{e}}$ results from

$\frac{p}{k_{B} T}=n_{\mathrm{e}}\left[1+\frac{1+\frac{K_{1}}{n_{\mathrm{e}}}+\frac{K_{1} K_{2}}{n_{\mathrm{e}}^{2}}}{\frac{K_{1}}{n_{\mathrm{e}}}+\frac{2 K_{1} K_{2}}{n_{\mathrm{e}}^{2}}}\right]$

Subsequently, the densities of the neutral and ionized species $n_{0}, n_{1}$, and $n_{2}$ can be obtained. Now all variables of Eq 3 are known so that the theoretical spectral line intensities $I_{j k}$ can be calculated at each wavelength $\lambda_{j k}$ depending on the temperature $T$.

The integrated theoretical emissivity $I_{\Delta \lambda}$ within each filter band width $\Delta \lambda$ of the CT equipment can thus be computed by summation of the line intensities $I_{j k}$ of the relevant ionization levels $i=0,1,2 \ldots$

$I_{\Delta \lambda}=\sum_{\Delta \lambda \text { filter }} \sum_{i} I_{j k}$

As with the calculated integrated emissivities, the ratios from all emissivity pairs measured through the three filters are computed in the relevant temperature range, e.g., from 5000 to $25,000 \mathrm{~K}$. Finally, comparing the calculated with the measured ratios allows the determination of the plasma temperature.

2.4.2 Examples of Results. The following tomographic investigations were carried out with a three-cathode TriplexPro $^{\mathrm{TM}}$ torch (Ref 35). The nozzle diameter was $9 \mathrm{~mm}$, the current was $540 \mathrm{~A}$, and the plasma gas flow was $50 \mathrm{slpm}$ Ar and $4 \mathrm{slpm} \mathrm{He}$. The resulting effective net power was $30.9 \mathrm{~kW}$. Figure 7 shows the tomographic reconstruction of gas temperature distribution with the powder injector plane cross section, three additional

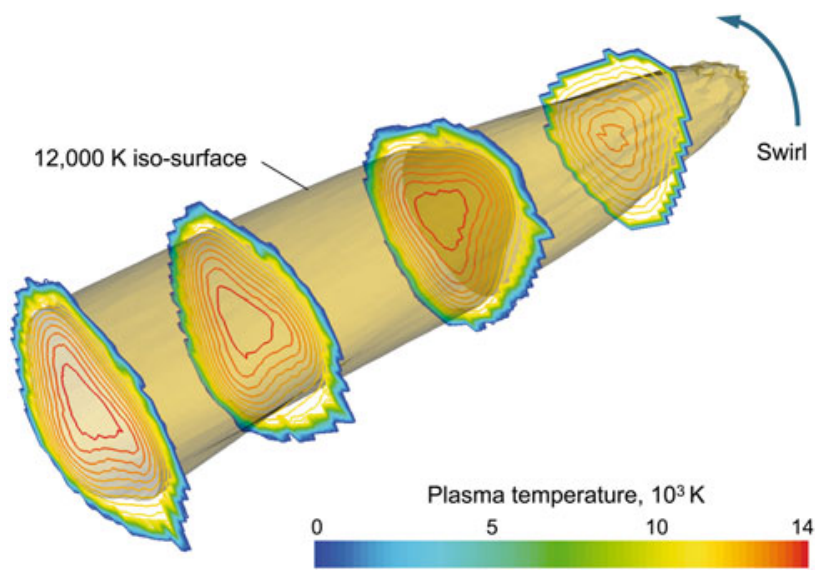

Fig. 7 Tomographic reconstruction of gas temperature distribution showing the counterclockwise jet rotation; injector plane cross section, three additional downstream sections and surface of $12000 \mathrm{~K}(\operatorname{Ref} 35)$ downstream sections and the iso-surface of $12,000 \mathrm{~K}$. The counterclockwise jet rotation is induced by the gas distribution ring inside the torch, to improve the interaction between the gas and the electric arcs near to the cathodes. The temperature distributions over the jet's cross section in the plane of particle injection show characteristic nonrotationally symmetric profiles with a typical triangular shape. This analysis confirmed that injecting the particles between two adjacent high-temperature cores corresponds to optimal conditions as the particles are kept properly and heated in the plasma jet (cage effect).

\section{Particle Temperature Measurement}

Particle temperature measurements usually rely on the measurement of the radiance of the hot, incandescent, particles in two or more wavelength or color bands. Such measurements are based on multicolor pyrometry, which relates intensities in two or more wavelength bands to temperature based on Planck's blackbody radiation law.

\subsection{Multicolor Pyrometry Principle}

The principle of multicolor pyrometry is described using the example of the two-color case. According to Planck's law, the spectral distribution of the thermal flux emitted by a surface element of an ideal black body can be expressed as

$E(\lambda)=\frac{K_{1}}{\lambda^{5}} \frac{1}{e^{K_{2} / \lambda T}-1}$

where $\lambda$ is the wavelength, $T$ is the temperature, $K_{1}$ is the first, and $K_{2}$ the second radiation constant

$$
\begin{array}{r}
K_{1}=2 \pi h c^{2}=3.741771 \times 10^{-16} \mathrm{Wm}^{2} \\
K_{2}=\frac{h c}{k_{B}}=1.438775 \times 10^{-2} \mathrm{mK}
\end{array}
$$

with $c$ the velocity of light, $h$ Planck's constant, and $k_{B}$ the Boltzmann constant.

The emissivity $\varepsilon$ gives the deviation of the radiation performance of a real body compared to an ideal black body. Values of $\varepsilon$ are material-specific and vary between zero and unity, and generally depend on the wavelength and temperature. Moreover, they can change due to surface oxidation or other chemical reactions.

Particle temperature measurement based on two-color pyrometry involves filtering of the thermal radiance emitted by a particle at two wavelength bands. The ratio of the measured radiation is

$$
\frac{E\left(\lambda_{1}\right)}{E\left(\lambda_{2}\right)}=\left(\frac{\lambda_{2}}{\lambda_{1}}\right)^{5} \frac{\varepsilon\left(\lambda_{1}\right) e^{K_{2} / \lambda_{2} T}-1}{\varepsilon\left(\lambda_{2}\right) e^{K_{2} / \lambda_{1} T}-1}
$$

Because the emissivities are unknown for many applications, the gray body assumption $\varepsilon\left(\lambda_{1}\right) / \varepsilon\left(\lambda_{2}\right)=1$ is used, where it is assumed that the emissivity is not dependent on the wavelength. However, in many cases this assumption is not fulfilled so that a systematic error is introduced which 
can lead to significant temperature deviations (Ref 36). For tungsten and molybdenum samples a measurement error of $50 \mathrm{~K}$ was found at 1600 and $300 \mathrm{~K}$ at $3654 \mathrm{~K}$, respectively (Ref 37 ).

Applying Wien's approximation of Planck's law for short wavelengths

$$
e^{K_{2} / \lambda T} \gg 1 \Rightarrow e^{K_{2} / \lambda T}-1 \approx e^{K_{2} / \lambda T}
$$

the desired temperature is obtained by

$$
T=\frac{K_{2}\left(\frac{1}{\lambda_{2}}-\frac{1}{\lambda_{1}}\right)}{\ln \left(\frac{E\left(\lambda_{1}\right)}{E\left(\lambda_{2}\right)}\left(\frac{\lambda_{1}}{\lambda_{2}}\right)^{5}\right)}
$$

The uncertainty of this approach generally increases with temperature because the measured intensity ratio $E\left(\lambda_{1}\right)$ / $E\left(\lambda_{2}\right)$ becomes less sensitive to changes in temperature according to Planck's function. On the other hand, this is partially offset by the increase in signal-to-noise ratio at higher temperatures (Ref 37).

In principle, the measured temperature represents the surface temperature which may differ from that in the particle core. However, oxide ceramics exhibit a large wavelength range where they are distinctly semi-transparent which may be phase dependent. Assuming that the particles' optical thickness is that of the product of the particle radius and the absorption coefficient, the measured value is not the surface temperature, since it is obtained in opaque materials, but rather the temperature of an internal layer. Such partial translucency is characteristic, e.g., of zirconia in the wavelength range of up to approximately $8 \mu \mathrm{m}$ (Ref 38 ), and is also found for other oxide ceramics, such as alumina (Ref 39).

\subsection{Calibration}

This relationship is common to both single particle and ensemble measurement methods. By forming the ratio, the measurement is insensitive to the absolute magnitude of radiation falling on the detector and the field of view need not be filled. The size of the particles is eliminated from the result. Moreover, a relative calibration, rather than a more difficult absolute calibration, is required.

One approach to calibrate such two-color pyrometers is to install the sensor head in a socket in front of a tungsten ribbon lamp. Prior to this, this lamp must be individually calibrated using a high-precision pyrometer. As a result, a calibration sheet provides some specific temperatures with corresponding currents and voltages. These calibration points are adjusted consecutively by a potentiometer and the temperature for each is measured. Finally, a regression function is fitted to the measured data linking the measured intensity ratios with the temperature values given in the calibration sheet. The parameters of the fitting function are the desired calibration constants. It should be noted that this calibration considers mainly the different sensitivities of the applied photoelectric detectors and is exactly valid only for the calibration lamp material and others with similar emissivity characteristics. The emissivities of many other substances may vary significantly from that of tungsten ( Ref 2). Moreover, the calibration is valid only in the temperature range in which the tungsten lamp is operated and for which calibration data is provided. Particle temperatures of high melting point materials such as YSZ may exceed this validity range.

Mates et al. (Ref 37) extended the validity range of calibration by the use of a unique nonintrusive temperature measurement facility providing an optically accessible target at a known, selectable absolute temperature up to the melting point of tungsten $(3693 \mathrm{~K})$ and combined it with a fiber-optic spectrometer to correct the calibration for nongray-body effects. They estimated the 95\% confidence intervals of their calibration as $1 \%$ at $1500 \mathrm{~K}$ and $2.5 \%$ at $3500 \mathrm{~K}$.

Another method to improve the calibration is to use a tungsten lamp in combination with a calibrated photodiode (Ref 40). The emissivity of the tungsten lamp is not assumed in this approach. Instead, the emitted light is separated by wavelength and measured with the photodiode; the same signal is measured with the sensor. This enables accurate characterization of the senor response to known incident light.

When pyrometry is performed with only two colors there is no measure to estimate whether or not particle emission is close to that of to a gray body; any measurement will match expected values for a gray body at some temperature since it is a determined problem. However, when three or more colors are used, the deviation from expected gray body behavior can be determined. This deviation is related to the magnitude of measurement error (Ref 40).

\subsection{Measurement Procedures}

A typical measurement procedure is as follows. The plasma gun is positioned in front of the optoelectronic sensor so that the measurement scope is within spraying distance of the work piece. The measuring head collecting the particle radiation is mounted on a scanning unit which moves it perpendicularly to the gun axis. Alternatively, the gun is moved relative to the fixed sensor head by the robot. Positioning accuracy should be $\pm 0.1 \mathrm{~mm}$ or better. Furthermore, sensors used for the closed-loop feedback controller, in particular, are fixed on the spray torch to continuously measure the flux characteristics.

Often, single-point measurements are performed. To do this, the particle flow is scanned before each measurement along the horizontal and vertical directions perpendicular to the jet axis to determine the point of maximum particle flow rate. This may be done by a twostep procedure with increasing resolution. Finally, the measurement position is determined at the detected maximum flux point. As an alternative, the centroid of the light intensity distribution is taken as a marker of the sweet spot of the plume.

If the sensor measurement volume is small when compared to the dimensions of the particle jet, a singlepoint measurement may not be representative as the particle characteristics vary spatially due to the sizedependence of the particle trajectories. In this case, it is 
critical to develop an appropriate approach with respect to positioning the measurement volume (Ref 40). Several measurements should be performed at different locations to cover the entire cross section of the plume. Furthermore, with respect to the particles deposited on the substrate, it must be considered which contribute the most to the deposited coating. If the evaluation of the measured values includes a weighting by volume, the particle's contribution to deposition is properly reflected. This eliminates the bias toward smaller particles inherent with simple averages by number and solves the problem that measurement points identified by maximum particle flow rates or light intensity are not coincident with the position of highest particle volume flux. However, volumeweighting requires a reliable determination of the particle diameters.

\subsection{Limitations and Errors}

The thermal emission of a particle depends not only on its temperature but also on its size and emissivity. As the emission intensity is proportional to the square of the diameter and the temperature to the power of four $\left(E \sim d^{2} T^{4}\right)$ the detectors and electronics must cover a wide dynamic range.

Particle detectability refers to the minimum amount of thermal radiation that a particle must emit for it to be detected by the sensor. This minimum particle intensity level depends on the optical arrangement, the detector sensitivity, the allowable exposure time, and background signal levels (Ref 37). The velocity and position of the particle within the field of view also affects its intensity signal. Finally, detection limits must be determined by experiment. For thermal spray processes with very small particles, such as suspension plasma or high velocity oxyfuel spraying, detectability of single particles is not possible. Only ensemble methods measuring several particles simultaneously, as described below, are applicable here (Ref 18, 41, 42).

Multicolor pyrometry may be affected by interfering nonthermal radiation. Figure 8 shows the sources which may greatly influence temperature measurements, namely (Ref 23, 43):

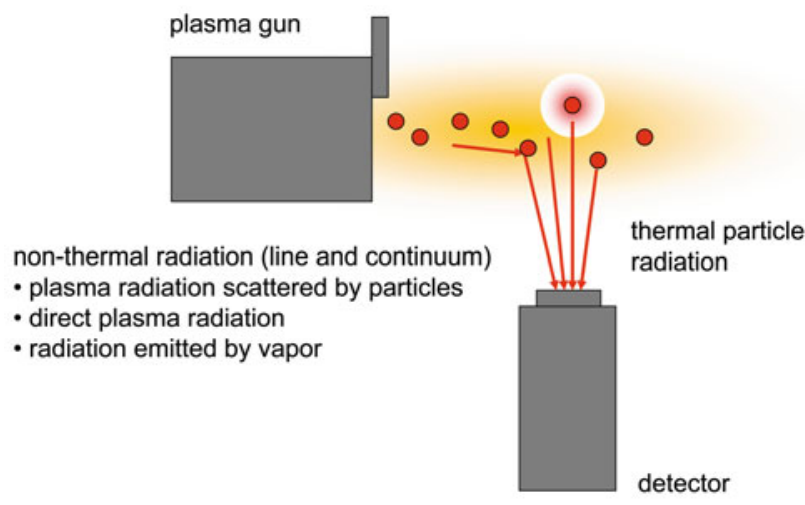

Fig. 8 Relevant nonthermal radiation sources influencing the temperature measurement using two-color pyrometry (Ref 36)
- Radiation emitted by the plasma surrounding the particle,

- Radiation emitted by evaporated particle material and impurities, and

- Radiation coming from the plasma source scattered by the particles.

As an optical sensor collects the total radiation including the nonthermal signals, the ratio of the measured intensities at the wavelengths used for multicolor pyrometry may be skewed. Generally, it is not sufficient to fix the wavelength bands between the most intense atomic lines of the plasma gas to exclude them because the emission also contains a continuous spectrum. Direct and scattered plasma radiation may become significant, if the particle radiation decreases, i.e., at lower temperatures and at small emissivities. Furthermore, the intensity of the plasma radiation is dependent on the excitation energy and the local gas concentration. Hence, the effect of nonthermal signals is especially large near the plasma torch exit and where there are few or relatively cool particles, such as those at the edges of the plume.

Based on spectroscopic measurements and using the Mie scattering theory, Gougeon et al. (Ref 44) calculated a measurement error of $+100 \mathrm{~K}$ for a $50 \mu \mathrm{m}$ nickel particle at $1550{ }^{\circ} \mathrm{C}$ located at $100 \mathrm{~mm}$ spray distance in an argon/ helium plasma assuming a two-color pyrometer operating at 877 and $995 \mathrm{~nm}$ wavelengths. Such errors due to scattered plasma light decrease at higher particle temperatures as well as at greater distances from the torch. Zalhi et al. (Ref 43) injected cold copper $+40-63 \mu \mathrm{m}$ particles at $120 \mathrm{~mm}$ spray distance into the plume of an F4 torch and measured the light scattered by them. The current was $700 \mathrm{~A}$ and the plasma gas $40 \mathrm{slpm} \mathrm{Ar}$ and $5 \mathrm{slpm} \mathrm{H}_{2}$. Using two-color pyrometry at $790 \pm 22$ and $995 \pm 22 \mathrm{~nm}$ and a tungsten ribbon calibration source, they calculated measurement errors of $25 \%$ at $1850{ }^{\circ} \mathrm{C}$ and $4 \%$ at $2520{ }^{\circ} \mathrm{C}$ surface temperature based on an emissivity of $\varepsilon=0.06$. With increasing emissivity, the measurement error decreased significantly, e.g., $2 \%$ at $1850{ }^{\circ} \mathrm{C}$ for $\varepsilon=0.2$.

Hollis et al. (Ref 45) reported measurements between the wavelengths of 630 and $880 \mathrm{~nm}$, showing that the plasma radiation dominates the nonthermal radiance further downstream, while near the torch exit, vapor signals of the particle material are found to be significant. By determining and subtracting the nonthermal signal from the collected spectra, more accurate particle temperatures could be achieved. Spraying molybdenum with +63 $-75 \mu \mathrm{m}$ powder size at approximately $30 \mathrm{~kW}$ with an ArHe plasma gas mixture, the corresponding correction was low $(1.5 \%)$ near the center of the radial particle distribution. At the edges of the distributions, the largest error of $14 \%$ was found.

\subsection{Sensor Systems}

Particle diagnostic systems can be distinguished by their detecting elements. The most common sensors fall into two main categories: (1) fiber-optic-based sensors that 
image the measurement volume onto a pair of photodetectors, and (2) CCD arrays (either 1D or 2D) that image the plume in a single line at a specific spray distance or along both the vertical and the spray directions (Ref 40).

Measurement techniques can also be categorized as single-particle and ensemble methods. Single-particle methods use high-speed pyrometry to estimate the temperature of individual particles. The mean and standard deviation of the particle temperature distribution can then be obtained from observations of sufficient numbers of individual particles. As fast pyrometers with response times of $100 \mathrm{~ns}$ are available, measurement times in the range of 10-20 s at constant spray conditions are sufficient for many applications. Single-particle techniques require the spray jet to be dilute enough so that single particles can be observed. This condition is met for many common thermal spray conditions (Ref 2). Ensemble methods observe large numbers of particles simultaneously and yield an estimated mean temperature directly, but cannot provide information on the shape or width of the particle temperature distribution. Furthermore, specific problems may be involved in this approach such as biasing the average results by the statistical distribution of the particle temperature and size (Ref 2, 40). They are not limited to lightly loaded sprays. Both the techniques are applied in the thermal spray industry. The single-particle techniques are preferable for scientific investigation, but are somewhat time-consuming and complicated to apply. Insensitivity to spray pattern position, coupled with fast response times, makes ensemble techniques attractive for control applications (Ref 2). However, a successfully operating closed loop system with a feedback of the particle characteristics to the process control is still a long-term objective (Ref 3,4) as knowledge about interrelations between particle characteristics and coating properties is incomplete and not unique. The particle state is important but may not fully describe the evolving deposit state (Ref 46).

As the number of available particle diagnostic systems is small they are briefly described as follows.

3.5.1 DPV-2000. The DPV-2000 (TECNAR Automation Ltd., St-Bruno, QC, Canada) was developed in the 1990s (Ref 47) and makes it possible to measure particle velocities, temperatures, and diameters. The velocity is obtained by measuring the time between the two signals which are triggered by a radiating particle passing the twoslit mask of the optoelectronic sensor head. The velocity can be calculated in conjunction with the distance of the slits and the magnification factor of the lens. The temperature is acquired by two-color pyrometry as described above. The wavelengths are at $\lambda_{1}=787 \pm 25 \mathrm{~nm}$ and $\lambda_{2}=995 \pm 25 \mathrm{~nm}$. The diameter is estimated from the radiation energy emitted at one wavelength assuming that the melted particles are spherical or almost spherical. Since it is necessary to know the real emissivity of the particle, a prior calibration by means of a powder with known diameter distribution has to be carried out. As the measurement volume is relatively small $\left(<1 \mathrm{~mm}^{2}\right)$, the data is collected for individual particles and can subsequently be analyzed statistically.
3.5.2 Accuraspray-g3. The Accuraspray-g3 diagnostic system (TECNAR Automation Ltd., St-Bruno, QC, Canada) is based on concepts similar to the DPV-2000 (Ref 48-50), but it provides ensemble average data representing the particle characteristics in a much larger measurement volume of approx. $\varnothing 3 \times 25 \mathrm{~mm}$. Particle velocities are obtained from cross-correlation of signals which are recorded at two locations in close proximity. The temperatures are again determined by two-color pyrometry. The other component of this system consists of a CCD camera enabling the analysis of the plume appearance (position, width, distribution, intensity) along a line at a spray distance perpendicular to the particle jet.

3.5.3 IPP. The Inflight Particle Pyrometer (IPP) sensor was developed by Inflight Ltd. Co., Idaho Falls, ID, USA. It is a two-color radiation pyrometer, with a long, cylindrical measurement volume $(\varnothing 5 \times 50 \mathrm{~mm})$ that provides an ensemble average particle temperature measurement at $10 \mathrm{~Hz}$ (Ref 51).

3.5.4 ThermaViz ${ }^{\mathrm{TM}}$. ThermaViz ${ }^{\mathrm{TM}}$ is a two-wavelength imaging pyrometer system (Stratonics Inc., Laguna Hills, CA, USA). It is based on a CCD camera (Ref 52, 53) with $640 \times 480$ pixels and a frame rate of $30 \mathrm{~Hz}$. Typical exposure times range from 5 to $20 \mu \mathrm{s}$. Besides ensemble particle velocities and sizes, temperatures are determined based on two-color pyrometry at wavelengths of 625 and $800 \mathrm{~nm}$.

3.5.5 SprayWatch ${ }^{\circledR}$. The developments leading to the SprayWatch $^{\circledR}$ diagnostic systems (Oseir Ltd., Tampere, Finland) began at the end of the 90s (Ref 54). A fast shutter CCD camera is used to create digital images of the spray. One typical specification of the CCD array was 1280 horizontal and 1024 vertical pixels, a spectral range 290 to $1000 \mathrm{~nm}$, and a maximum frame rate of $7 \mathrm{~Hz}$ (Ref 55). The covered measurement volume is adjustable from $18 \times 14 \times 5$ to $36 \times 28 \times 30 \mathrm{~mm}^{3}$.

Digital images taken with short exposure times are processed by an algorithm identifying individual particles in the images and measuring their position, direction, and velocity. The latter images are obtained from the analysis of streak lines. Thus, the system provides a continuous measurement of particle velocities and flow, spray vertical position, width, angle, and divergence. Furthermore, the camera also takes images using a longer exposure time to determine the average particle temperature by two-color pyrometry. For this purpose, an optical double-stripe filter is integrated in the camera and covers a part of the CCD detector so that the measurement volume is imaged on the CCD array in two different wavelengths.

3.5.6 Flux Sentinel. The Flux Sentinel sensor (Cyber Materials LLC, Boston, MA, USA) (Ref 40, 56) is a CCDbased sensor capable of sensing individual particle temperatures, diameters, and velocities. An array column is used with a resolution of $3.5 \mu \mathrm{m}$ to directly measure particle diameter and, since the array is long enough, it can measure particles from across the whole plume. Particle diameter is estimated photometrically. Multiple-color pyrometry is used to determine the temperature for each particle using $125 \mathrm{~nm}$ wide color bands in regions where a significant intensity is emitted for a gray body above

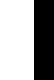


$2000 \mathrm{~K}$. Assuming gray-body emission from the particles, the map from temperature to intensity for each color band is found by integrating Planck's blackbody radiation function for each temperature against the known spectral sensitivity of the sensor. The temperature is then found using a least square's fit of the relative values of measured intensity in the multiple color bands compared to such calculated values. Frames are sampled at $500 \mathrm{~Hz}$ and since the exposure time is longer than the particle's transit time across the measurement volume, multiple particles are captured in each frame. Particle velocity is calculated through the Stefan-Boltzmann law via the sum of intensity from all pixels in one particle's image, which is approximately proportional to the surface area of the particle, the particle velocity, and temperature to the fourth power. This approach needs a prior calibration. In addition to individual particle statistics, also overall light intensity measurements representing the sum of all imaged particles are provided by means of long integration times or averages of many frames from the CCD array.

3.5.7 NIR Sensor. The principle of the near-infrared sensor (NIR Sensor, GTV Verschleißschutz GmbH, Luckenbach, Germany) (Ref 57) is based on the illumination of single particles in the focus distance by a $10 \mathrm{MHz}$ pulsed infrared laser $(1000 \mathrm{~nm})$, whereby the reflected pulsed laser radiation indicates the passage of single particles through the measurement focus spot. The in-flight time is inversely proportional to the particle velocity. Furthermore, during the time of passage the emitted thermal radiation of the single particles is captured by two fast detectors with different spectral ranges between 900 and $1500 \mathrm{~nm}$ as well as between 1500 and $2600 \mathrm{~nm}$. The ratio of the two emission signals is used for temperature determination according to the two-color pyrometry principle. As up to 300,000 single particles per second are detected, statistical distributions and average values can be calculated. Due to operation in the infrared range and due to the pulsed laser illumination, comparatively cold and slow particles are still detectable.

\subsection{Comparative Tests}

Comparative particle temperature measurements with the DPV-2000 and the Accuraspray-g3 diagnostic systems were carried out with a Multicoat facility (Sulzer Metco AG, Wohlen, Switzerland) when using both a single cathode F4 and a multi-cathode Triplex II torch mounted on a six-axis robot for atmospheric plasma spraying (Ref 58). The powder was 8 wt.\% yttria partially stabilized zirconia Sulzer Metco 204NS. The particle diameter distribution was $d_{10}=25 \mu \mathrm{m}, d_{50}=57 \mu \mathrm{m}, d_{90}=101 \mu \mathrm{m}$, the morphology was spheroidal. The spray parameters are listed in Table 1; for the Triplex II torch, three different powder feed rates were used.

The DPV-2000 measurements of particle velocities and temperatures were carried out on a $7 \times 7$ point grid in a plane normal to the gun axis at stand-off distance. For the F4 torch, the grid was had dimensions of $12 \times 12 \mathrm{~mm}^{2}$ and for the Triplex II gun $24 \times 24 \mathrm{~mm}^{2}$, respectively. The measurement grid for the Triplex II gun had to be en-
Table 1 Spraying parameters for comparative measurements of particle temperatures

\begin{tabular}{|c|c|c|}
\hline & F4 & Triplex II \\
\hline Current, A & 660 & 500 \\
\hline Plasma gas & $\begin{array}{l}40 \text { slpm Ar, } \\
10 \text { slpm H2 }\end{array}$ & 40 slpm Ar, 10 slpm He \\
\hline Carrier gas & $3.5 \mathrm{slpm} \mathrm{Ar}$ & $1.6 \mathrm{slpm} \mathrm{Ar}$ \\
\hline Powder feed rate & $8.5 \mathrm{~g} \mathrm{~min}^{-1}(5 \%)$ & $\begin{array}{l}8.5 / 17 / 34 \mathrm{~g} \mathrm{~min}^{-1} \\
(5 / 10 / 20 \%)\end{array}$ \\
\hline $\begin{array}{l}\text { Stand-off } \\
\quad \text { distance, mm }\end{array}$ & 100 & 175 \\
\hline
\end{tabular}

larged compared to the grid used for the F4 gun, because with the Triplex II gun the particle flux was found to be not as concentrated as with the F4 gun. Before making the measurements, the sensor head was centered by the DPV2000 autocenter function so that the central point of the measurement grid $(x=0 \mathrm{~mm}, y=0 \mathrm{~mm})$ is relative to the maximum particle flux. The Accuraspray-g3 sensor was adjusted to the maximum plume intensity, which was determined by the CCD camera component of the system.

When comparing the measured particle velocities and temperatures with those delivered by the DPV-2000 system, it has to be considered that the Accuraspray-g3 data are average values representing a wide particle fraction in a comparatively large measurement volume. Regarding the length of the Accuraspray-g3 measurement volume of $25 \mathrm{~mm}$, it is obvious that it covers the entire width of the applied DPV-2000 measurement grid. As the Accuraspray-g3 system averages particle data on the whole measurement volume to one single representative value, a weighting by the particle frequency is thus implied. The same procedure has to be performed with the data measured by the DPV-2000 to ensure comparability. Thus, the local mean values of the particle data at each DPV-2000 grid point which is contained by the Accuraspray-g3 measurement volume must be weighted by the local particle flow rates to achieve one global mean value. Figure 9 shows a comparison of the results. In each case, the lefthand column of the column pairs represents the Accuraspray-g3 achievements; the right-hand columns depict the flux weighted and averaged DPV-2000 data. Comparisons are shown for one application of the F4 gun and three different powder feed rates applied to the Triplex II gun, depicted by the percentage values.

The comparison of the particle temperatures shows the largest differences for the $\mathrm{F} 4$ gun as $-10 \%$. The reason is that a smaller measurement grid was used for the F4 gun. The Accuraspray-g3 measurement volume was obviously longer than the width of the measurement grid. Therefore low-temperature particles which are not covered by the DPV-2000 measurement were acquired at the margins of the Accuraspray-g3 measurement volume and therefore reduced the average values. As a consequence, the Accuraspray-g3 results should typically be somewhat lower than the average values based on the DPV-2000 measurements.

Using the Triplex II gun, a larger measurement grid was applied. The side length corresponds approximately to 


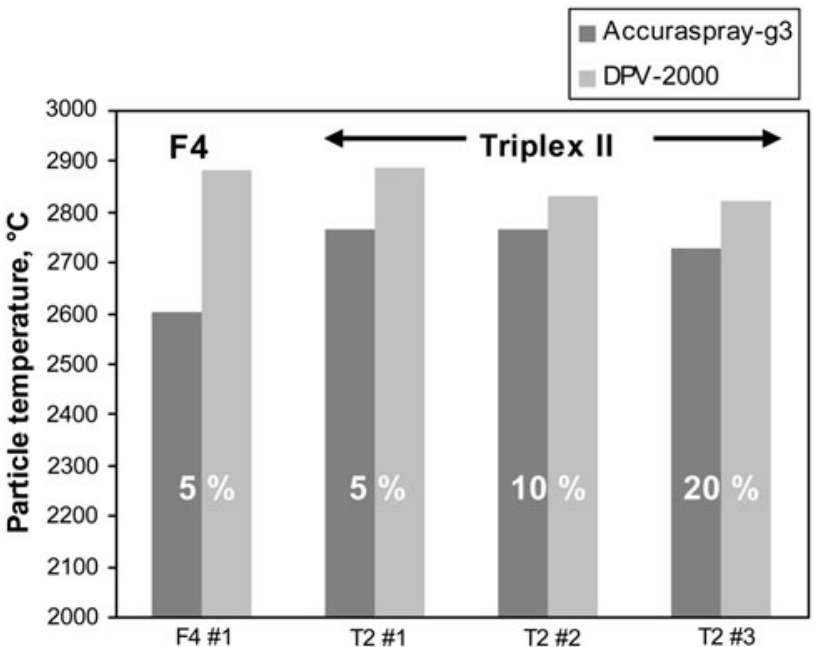

Fig. 9 Comparison of mean particle temperature based on DPV-2000 and Accuraspray-g3 measurements using the F4 and the Triplex II gun (58); percentage values refer to the powder feed rate as indicated in Table 1

the length of the Accuraspray-g3 measurement volume. Hence, the differences between the DPV-2000 and the Accuraspray-g3 results are reduced to $-2 /-4 \%$. Considering the differences between the DPV-2000 and Accuraspray-g3 diagnostic systems as a function of their different operating principles, the results are found to be in good agreement.

\subsection{Examples of Results}

Figure 10 shows the DPV-2000 particle temperature distributions measured at $175 \mathrm{~mm}$ stand-off distance applying a Triplex II torch. The powder was $8 \mathrm{wt} \%$ yttria partially stabilized zirconia Sulzer Metco 204NS-G (Ref 36). The particle diameter distribution was $d_{10}=12 \mu \mathrm{m}$, $d_{50}=45 \mu \mathrm{m}, d_{90}=88 \mu \mathrm{m}$, and the morphology was hollow spherical. Each temperature distribution contains at least 5,000 single particle data. Various input power levels were achieved by setting the current between 350 and $525 \mathrm{~A}$. It is found that the distributions are bimodal in the medium and lower power range. The frequency distributions contain two fractions, one at a constant mean temperature, and another at a mean temperature which varies with the power. Accordingly, the measured particle temperature distributions can be approximated by one or two Gaussian normal distribution functions, respectively.

It is assumed that the mean temperature of the partial particle temperature distribution located at a constant temperature is the melting temperature of the powder feedstock material. Since the particles cool when they approach the substrate, their fusion enthalpy is released when the melting/solidifying temperature is reached. As this takes time, the residence probability of the particle at melting temperature is greater than at other temperatures below or above the melting point. However, the peak of the normal distribution at constant mean temperature was measured at approximately $2400{ }^{\circ} \mathrm{C}$, whereas the melting
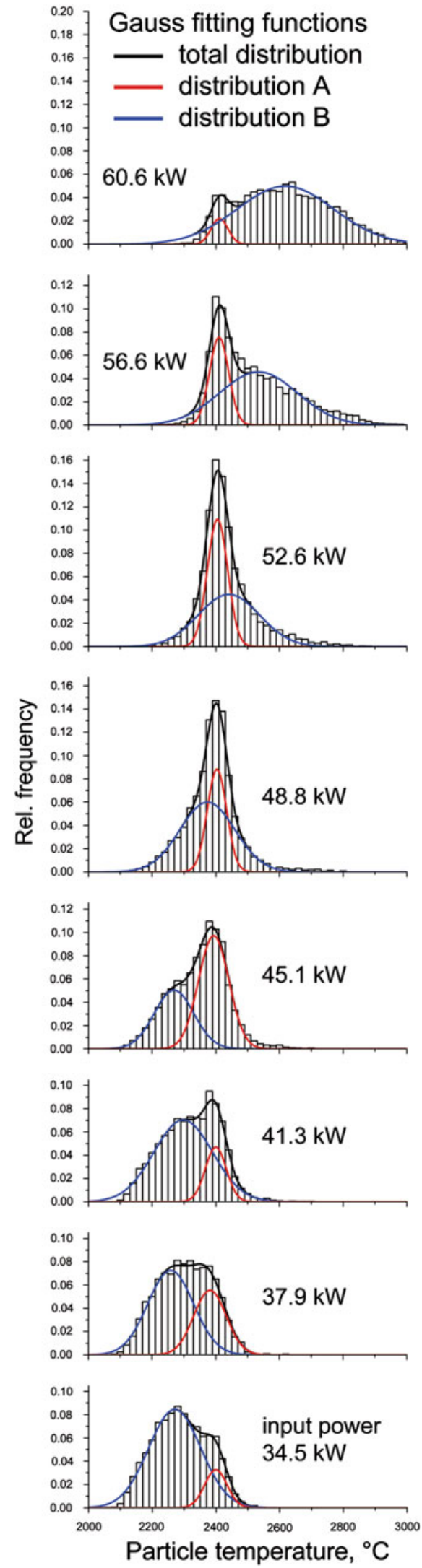

Fig. 10 Particle temperature distributions for the YSZ powder measured by DPV-2000 for different torch powers (Ref 36) 


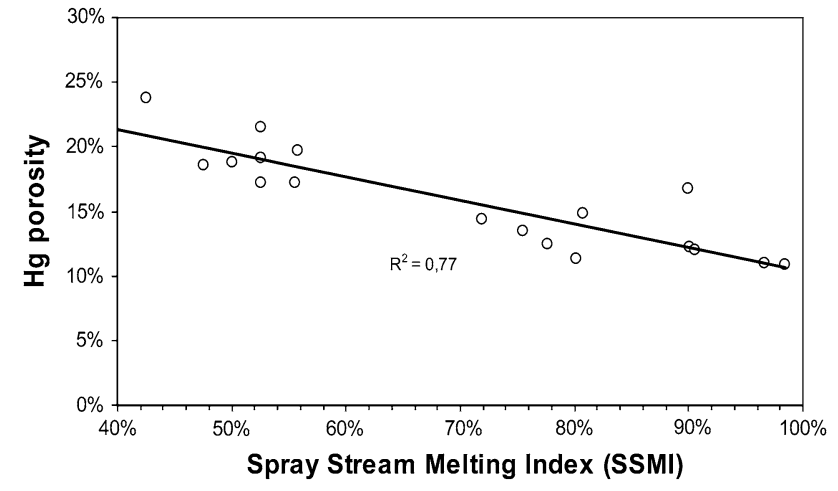

Fig. 11 Fraction of molten particles relative to the total number of particles (Ref 61) (Spray Stream Melting Index, SSMI according to Ref 60

temperature of $\mathrm{YSZ}$ is $2710^{\circ} \mathrm{C}$. This deviation can be explained by systematic and material-dependent measurement errors by two-color pyrometry (Ref 36). The peaks at variable positions below and above the apparent melting temperature are associated with already solidified and still liquid particles, respectively.

Similar measurements and analyses of YSZ are reported in Ref 59. Here, it is also stated that the temperature distributions provide information on the melting status of the particles. One portion of the particles was found to have the same mean temperature at various spraying parameters. Different particle morphologies were reported to give similar peaks at the same temperature. This may prove that after melting the liquid particles have similar characteristics and that the constant peak temperature can be related to the melting temperature. Likewise, there are discrepancies between the measured and the referenced melting temperatures.

The fractions of solidified, solidifying, and molten particles were evaluated quantitatively for a number of investigated parameter sets. They correspond to the areas below the respective Gaussian curves fitted to the temperature distributions. Srinivasan and Sampath (Ref 60) proposed the Spray Stream Melting Index (SSMI), which is the ratio of molten particles to the total number of particles. The particles just solidifying are assumed to be one half molten and one half solid. The individual particle volumes are not considered. Figure 11 shows that there is a good correlation of the porosity and the Spray Stream Melting Index confirming the important role of the particle temperature (Ref 61). According to the regression line, 55 to $60 \%$ of the particles must be molten to obtain approximately $18 \%$ porosity.

\section{Conclusion}

An essential requirement of diagnostic methods in thermal spray is the accurate measurement of temperatures. This refers to the hot working gases as well as to the in-flight temperature of the particles. This article gives a review of plasma and particle temperature measurement methods.
The plasma temperature measurement techniques of enthalpy probe and optical emission spectroscopy are typical tools for research and development. As enthalpy probes are intrusive methods they have only limited capability to resist high thermal loads. Thus, they can be applied only at lower plasma power or larger distances from the torch. In contrast, optical emission spectroscopy has the advantage of being a non-contact method it is therefore also possible to make measurements close to the nozzle. However, the atomic lines must be selected carefully as absorption may affect the evaluation. Moreover, at atmospheric conditions this method is impeded by broadening effects and continuous background radiation. The validity of the results is only given at local thermal equilibrium conditions. Computer tomography is versatile with regard to multi-electrode torches as it does not rely on axial symmetric conditions. However, it is much more complex and needs sophisticated software to reconstruct the temperature distributions.

In-flight measurement of particle temperatures is an important way to monitor and optimize thermal spray processes. Ensemble measuring techniques are more practical for industrial applications, but their results are less meaningful. In comparison, the statistical density distributions of the particle temperature determined by single-particle techniques provide revealing insights into the particle melting state, which is a key feature for yielding specific coating characteristics. Although such distributions are self-consistent, the absolute accuracy of the multicolor methods is generally weak due to poor knowledge of the emissivity characteristics of the sprayed materials.

Notwithstanding the great efforts which have been made to further develop diagnostic tools and the improvements in understanding thermal spray processes thus achieved, a successfully operating closed-loop system with a feedback of the particle characteristics to the process control is still a long-term objective as the knowledge about interrelations between particle characteristics and coating properties is incomplete.

\section{Acknowledgments}

The authors gratefully acknowledge many useful discussions on plasmaphysical issues with Dr. José-Luis Marqués (Universität der Bundeswehr München, Institut für Plasmatechnik und Mathematik) as well as the support of Alexandre Guignard on suspension plasma spray experiments, Andreas Hospach on optical emission spectroscopic measurements, and Karl-Heinz Rauwald on enthalpy probe measurements (all Forschungszentrum Jülich GmbH, Institut für Energie-und Klima forschung).

\section{References}

1. P. Fauchais, J.F. Coudert, M. Vardelle, A. Vardelle, and A. Denoirjean, Diagnostics of Thermal Spraying Plasma Jets, J. Therm. Spray Technol., 1992, 1(2), p 117-128 
2. J.R. Fincke, D.C. Haggard, and W.D. Swank, Particle Temperature Measurement in the Thermal Spray Process, J. Therm. Spray Technol., 2001, 10(2), p 255-266

3. J.F. Coudert, P. Fauchais, and M. Vardelle, Diagnostics of Plasma Spray Process and Derived On-Line Control, High Temp. Mater. Process., 2002, 6(2), p 247-265

4. P. Fauchais and M. Vardelle, Sensors in Spray Processes, $J$. Therm. Spray Technol., 2010, 19(4), p 668-694

5. J.R. Fincke, W.D. Swank, S.C. Snyder, and D.C. Haggard, Enthalpy Probe Performance in Compressible Thermal Plasma Jets, Rev. Sci. Instrum., 1993, 64(12), p 3585-3593

6. M. Rahmane, G. Soucy, and M.I. Boulos, Analysis of the Enthalpy Probe Technique for Thermal Plasma Diagnostics, Rev. Sci. Instrum., 1995, 66(6), p 3424-3431

7. A. Capetti and E. Pfender, Probe Measurements in Argon Plasma Jets Operated in Ambient Argon, Plasma Chem. Plasma Process., 1989, 9(2), p 329-341

8. W.L.T. Chen, J. Heberlein, and E. Pfender, Diagnostics of a Thermal Plasma Jet by Optical Emission Spectroscopy and Enthalpy Probe Measurements, Plasma Chem. Plasma Process., 1994, 14(3), p 317-332

9. E. Pfender, Plasma Jet Behavior and Modeling Associated with the Plasma Spray Process, Thin Solid Films, 1994, 238, p 228-241

10. H.-D. Steffens and T. Duda, Enthalpy Measurements of Direct Current Plasma Jets Used for $\mathrm{ZrO}_{2} \cdot \mathrm{Y}_{2} \mathrm{O}_{3}$ Thermal Barrier Coatings, J. Therm. Spray Technol., 2000, 9(2), p 235-240

11. M. Rahmane, G. Soucy, M.I. Boulos, and R. Henne, Fluid Dynamic Study of Direct Current Plasma Jets for Plasma Spraying Applications, J. Therm. Spray Technol., 1998, 7(3), p 349-356

12. A. Denoirjean, O. Lagnoux, P. Fauchais, V. Sember, Oxidation Control in Atmospheric Plasma Spraying: Comparison between $\mathrm{Ar} / \mathrm{H}_{2} / \mathrm{He}$ and $\mathrm{Ar} / \mathrm{H}_{2}$ Mixtures, Thermal Spray: Meeting the Challenges of the 21st Century, C. Coddet, Ed., May 25-29, 1998 (Nice, France), ASM International, 1998, p 809-814

13. J.-E. Döring, J.-L. Marqués, R. Vaßen, D. Stöver, The Influence of Plasma Characteristics on Particle Properties during Plasmaspraying of Yttria Stabilized Zirconia Using a Triplex Torch, Thermal Spray 2004: Advances in Technology and Application, ASM International, May 10-12, 2004 (Osaka, Japan), ASM International, 2004

14. J. Grey, P.F. Jacobs, and M.P. Sherman, Calorimetric Probe for the Measurement of Extremely High Temperatures, Rev. Sci. Instrum., 1962, 33(7), p 738-741

15. W.D. Swank, J.R. Fincke, and D.C. Haggard, Modular Enthalpy Probe and Gas Analyzer for Thermal Plasma Measurements, Rev. Sci. Instrum., 1993, 64(1), p 56-62

16. J.-E. Döring, R. Vaßen, and D. Stöver, Influence of Carrier Gas Flow and Liquid Injection in the Plasma Jet on Plasma Characteristics During the Atmospheric Plasma Spray Process, Thermal Spray 2003: Advancing the Science \& Applying the Technology, C. Moreau and B. Marple, Ed., ASM International, Orlando, 2003, p 641-647

17. R. Vaßen, H. Kaßner, G. Mauer, and D. Stöver, Suspension Plasma Spraying: Process Characterization and Applications, $J$. Therm. Spray Technol., 2010, 19(1-2), p 219-225

18. G. Mauer, A. Guignard, R. Vaßen, and D. Stöver, Process Diagnostics in Suspension Plasma Spraying, Surf. Coat. Technol., 2010. doi: 10.1016/j.surfcoat.2010.03.007

19. E. Pfender, J. Fincke, and R. Spores, Entrainment of Cold Gas into Thermal Plasma Jets, Plasma Chem. Plasma Process., 1991, 11(4), p 529-543

20. S. Yugeswaran and V. Selvarajan, Excitation Temperature and Electron Number Density Behavior of Atmospheric Pressure D.C. Argon Plasma Jet during Spheroidization of Nickel, Vacuum, 2009, 83, p 841-847

21. K. Wittmann, F. Blein, J.F. Coudert, and P. Fauchais, Control of the Injection of an Alumina Suspension Containing Nanograins in a dc Plasma, Thermal Spray 2001: New Surfaces for a New Millennium (Singapore), C.C. Berndt, K.A. Khor, and E.F. Lugscheider, Ed., ASM International, Materials Park, OH, 2001, p 375-382
22. A. Marotta, Determination of Axial Thermal Plasma Temperatures Without Abel Inversion, J. Phys. D Appl. Phys., 1994, 27, p 268-272

23. K. Hollis and R. Neiser, Analysis of the Nonthermal Emission Signal Present in a Molybdenum Particle-Laden Plasma-Spray Plume, J. Therm. Spray Technol., 1998, 7(3), p 383-391

24. J.L. Margrave, Ed., The Characterization of High Temperature Vapors, Wiley, New York, NY, 1967

25. D.R. Lide, Ed., CRC Handbook of Chemistry and Physics, 89th Edition (Internet Version 2009), CRC Press/Taylor and Francis, Boca Raton, FL, 2009

26. S. Semenov and B. Cetegen, Spectroscopic Temperature Measurements in Direct Current Arc Plasma Jets Used in Thermal Spray Processing of Materials, J. Therm. Spray Technol., 2001, 20(2), p 326-336

27. X. Tu, B.G. Chéron, J.H. Yan, and K.F. Cen, Electrical and Spectroscopic Diagnostic of an Atmospheric Double Arc Argon Plasma Jet, Plasma Sour. Sci. Technol., 2007, 16, p 803-812

28. Z. Salhi, D. Klein, P. Gougeon, and C. Coddet, Development of Coating by Thermal Plasma Spraying Under Very Low-Pressure Condition $<1$ mbar, Vacuum, 2005, 77, p 145-150

29. W.L.T. Chen, J. Heberlein, and E. Pfender, Diagnostics of a Thermal Plasma Jet by Optical Emission Spectroscopy and Enthalpy Probe Measurements, Plasma Chem. Plasma Process., 1994, 14(3), p 317-332

30. M. Rajabian, D.V. Gravelle, and S. Vacquié, Measurements of Temperatures and Electron Number Density in an Argon-Helium Plasma Jet Generated by a dc Torch-Operation Close to Supersonic Threshold, Plasma Chem. Plasma Process., 2004, 24(2), p 261-284

31. N.K. Joshi, S.N. Sahasrabudhe, K.P. Sreekumar, and N. Venkatramani, Variation of Axial Temperature in Thermal Plasma Jets, Meas. Sci. Technol., 1997, 8, p 1146-1150

32. Y. Ralchenko, A.E. Kramida, J. Reader, and NIST ASD Team, NIST Atomic Spectra Database (version 3.1.5), http:// physics.nist.gov/asd3 [2009, October 19], 2008, National Institute of Standards and Technology, Gaithersburg, MD

33. K. Landes, Diagnostics in Plasma Spraying Techniques, Surf. Coat. Technol., 2006, 201, p 1948-1954

34. J.-L. Marqués, G. Forster, and J. Schein, Multi-Electrode Plasma Torches: Motivation for Development and Current State-of-theArt, Open Plasma Phys. J., 2009, 2, p 89-98

35. G. Mauer, R. Vaßen, D. Stöver, S. Kirner, J.-L Marqués, S. Zimmermann, G. Forster, and J. Schein, Improving Powder Injection in Plasma Spraying by Optical Diagnostics of the Plasma and Particle Characterization, Thermal Spray: Global Solutions fur Future Applications, Vol 264, May 3-5, 2010, Singapore, DVSBerichte DVS Media, Düsseldorf, Germany, 2010, p 525-530

36. G. Mauer, R. Vaßen, and D. Stöver, Detection of Melting Temperatures and Sources of Errors Using Two-Color Pyrometry During In-flight Measurements of Atmospheric Plasma-Sprayed Particles, Int. J. Thermophys., 2008, 29, p 764-786

37. S.P. Mates, D. Basak, F.S. Biancaniello, S.D. Ridder, and J. Geist, Calibration of a Two-Color Imaging Pyrometer and Its Use for Particle Measurements in Controlled Air Plasma Spray Experiments, J. Therm. Spray Technol., 2002, 11(2), p 195-205

38. J.I. Eldridge, C.M. Spuckler, K.W. Street, and J.R. Markham, Infrared Radiative Proper-ties of Yttria-Stabilized Zirconia Thermal Barrier Coatings, Ceram. Eng. Sci. Proc., 2002, 23(4), p 417-430

39. V. Sarou-Kanian, J.C. Rifflet, and F. Millot, IR Radiative Properties of Solid and Liquid Alumina: Effects of Temperature and Gaseous Environment, Int. J. Thermophys., 2005, 26(4), p 12631275

40. D. Wroblewski, G. Reimann, M. Tuttle, D. Radgowski, M. Cannamela, S.N. Basu, and M. Gevelber, Sensor Issues and Requirements for Developing Real-Time Control for Plasma Spray Deposition, J. Therm. Spray Technol., 2010, 19(4), p 723-735

41. J. Oberste Berghaus, S. Bouaricha, J.-G.Legoux, and C. Moreau, Thermal Spray 2005: Building on 100 Years of Success, E. Lugscheider, Ed., May 2-4, 2005 (Basel, Switzerland), Verlag für

. 
Schweißen und verwandte Verfahren DVS-Verlag GmbH, 2005, p 512-518

42. J. Oberste Berghaus and B.R. Marple, High-Velocity Oxy-Fuel (HVOF) Suspension Spraying of Mullite Coatings, J. Therm. Spray Technol., 2008, 17(5-6), p 671-678

43. Z. Salhi, P. Gougeon, D. Klein, and C. Coddet, Influence of Plasma Light Scattered by In-Flight Particle on the Measured Temperature by High Speed Pyrometry, Infrared Phys.Technol., 2005, 46(5), p 394-399

44. P. Gougeon and C. Moreau, In-Flight Particle Surface Temperature Measurement: Influence of the Plasma Light Scattered by the Particles, J. Therm. Spray Technol., 1993, 2(3), p 229-233

45. K. Hollis and R. Neiser, Particle Temperature and Flux Measurement Utilizing a Nonthermal Signal Correction Process, $J$. Therm. Spray Technol., 1998, 7(3), p 392-402

46. S. Sampath, V. Srinivasan, A. Valarezo, A. Vaidya, and T. Streibl, Sensing, Control, and In Situ Measurement of Coating Properties: An Integrated Approach Toward Establishing Process-Property Correlations, J. Therm. Spray Technol., 2009, 18(2), p 243-255

47. C. Moreau, P. Gougeon, M. Lamontagne, V. Lacasse, G. Vaudreuil, and P. Cielo, On-Line Control of the Plasma Spraying Process by Monitoring the Temperature, Velocity, and Trajectory of In-Flight Particles, Thermal Spray Industrial Applications, C.C. Berndt and S. Sampath, Ed., ASM International, Boston, MA, 1994, p 431-437

48. G. Bourque, M. Lamontagne, and C. Moreau, A New Sensor for On-line Monitoring the Temperature and Velocity of Thermal Spray Particles, Thermal Spray: Surface Engineering via Applied Research, C.C. Berndt, Ed., ASM International, Montréal, QC, 2000, p 45-50

49. L. Pouliot, J. Blain, F. Nadeau, M. Lamontagne, J.F. Bisson, and C. Moreau, Significant Increase in the Sensitivity of In-flight Particle Detector Through Improvements and Innovation, Thermal Spray 2001: New Surfaces for a New Millennium, C.C. Berndt, K.A. Khor, and E.F. Lugscheider, Ed., ASM International, Singapore, 2001, p 723-726

50. J.F. Bissons, M. Lamontagne, C. Moreau, L. Pouliot, J. Blain, and F. Nadeau, Ensemble In-flight Particle Diagnostics Under Thermal Spray Conditions, Thermal Spray 2001: New Surfaces for a New Millennium, C.C. Berndt, K.A. Khor, and E.F. Lugscheider, Ed., ASM International, Singapore, 2001, p 705-714

51. W.D. Swank, J.R. Fincke, and D.C. Haggard, A Particle Temperature Sensor for Monitoring and Control of the Thermal Spray Process, Advances in Thermal Spray Science \& Technology, C.C. Berndt and S. Sampath, Ed., ASM International, Houston, TX, 1995, p 111-116
52. J.E. Craig, R.A. Parker, F.S. Biancaniello, S.D. Ridder, and S.P. Mates, Particle Temperature Measurements by Spectroscopic and Two-Wavelength Streak Imaging, Thermal Spray: Surface Engineering via Applied Research, C.C. Berndt, Ed., ASM International, Montréal, QC, 2000, p 51-56

53. J.E. Craig, R.A. Parker, D.Y. Lee, T. Wakeman, J. Heberlein, and D. Guru, Particle Temperature and Velocity Measurements by Two-Wavelength Streak Imaging, Thermal Spray 2003: Advancing the Science and Applying the Technology, Vol 2, B.R. Marple and C. Moreau, Ed., ASM International, Orlando, FL, 2003, p 1107-1112

54. J. Vattulainen, J. Knuuttila, T. Lehtinen, and T. Mantyla, InFlight Particle Concentration and Velocity Measurements in Thermal Spraying Using a Non-Intensified CCD Camera, Thermal Spray: Meeting the Challenges of the 21st Century, C. Coddet, Ed., ASM International (Nice, France), 1998, p 767-772

55. J. Vattulainen, E. Hämäläinen, R. Hernberg, P. Vuoristo, and T. Mäntylä, Novel Method for In-Flight Particle Temperature and Velocity Measurements in Plasma Spraying Using a Single CCD Camera, J. Therm. Spray Technol., 2001, 10(1), p 94-104

56. M. Gevelber, D. Wroblewski, B. Vattiat, O. Ghosh, M. VanHout, and S.N. Basu, Issues and Requirements for Developing a Plasma Spray Deposition Rate Sensor for Real-Time Control, Thermal Spray 2008: Thermal Spray Crossing Borders (Maastricht, The Netherlands), E. Lugscheider, Ed., Verlag für Schweißen und verwandte Verfahren DVS-Verlag GmbH, Düsseldorf, Germany, 2008, p 912-916

57. A. Schwenk, A. Wank, T. Wallendorf, and S. Marke, NIR (NearInfra-Red) sensor-an alternative diagnostic tool for the online process control of thermal spray processes, Thermal Spray: Global Solutions for Future Applications (Singapore), DVS-Berichte, Vol 264, DVS Media, Düsseldorf, Germany, 2010, p 135-138

58. G. Mauer, R. Vaßen, and D. Stöver, Comparison and Applications of DPV-2000 and Accuraspray-g3 Diagnostic Systems, J. Therm. Spray Technol., 2007, 16(3), p 414-424

59. T. Streibl, A. Vaidya, M. Friis, V. Srinivasan, and S. Sampath, A Critical Assessment of Particle Temperature Distributions During Plasma Spraying: Experimental Results for YSZ, Plasma Chem. Plasma Process., 2006, 26(1), p 73-102

60. V. Srinivasan and S. Sampath, Estimation of Molten Content of the Spray Stream from Analysis of Experimental Particle Diagnostics, J. Therm. Spray Technol, 2010, 19(1-2), p 476-483

61. G. Mauer, M.O. Jarligo, D.E. Mack, R. Vaßen, and D. Stöver, Development of Plasma Spray Parameters for Ceramic Coatings in Gas Turbines, 24th International Conference on Surface Modification Technologies (SMT24), Sept 7-9, 2010 (Dresden, Germany), conference proceedings to be published 